\title{
Unequal Times: Social Structure, Temporal Perspective, and Time Allocation in Poland
}

\author{
Ewa Jarosz ${ }^{1,2}$ (iD
}

Accepted: 17 February 2018 / Published online: 26 February 2018

(C) The Author(s) 2018. This article is an open access publication

\begin{abstract}
This study explored the links between individual's time perspective and their structural position as well as related this perspective to how people spend their time. Time perspective was defined by individual's scores on two distinct factors-future-orientation and clock-orientation. These factors were analysed jointly in order to account for how people organized their time within a short-term (clock-orientation) and a long-term (futureorientation) horizon. Temporal orientations were socially differentiated, primarily by education and income. Better educated individuals were more future-oriented, while those with higher income showed preference for more rigid clock-based organization of time on a daily basis. Both orientations were also related to how time was spent. Clock-oriented individuals allocated significantly more time to paid work and less time to social life or personal time. Future-oriented respondents spent more time on personal life and physical exercise. These findings suggest that temporal orientations are linked to how much time individuals allocate to both market and non-market activities, net of their other social characteristics. The study casts light on the much overlooked dimension of social inequalitythe temporal one, and links individual's structural position, attitudes towards time, and time-use patterns.
\end{abstract}

Keywords Social structure $\cdot$ Temporal orientations $\cdot$ Time perspective $\cdot$ Time allocation · Poland

Ewa Jarosz

ewa.jarosz@sociology.ox.ac.uk

1 Department of Sociology, Centre for Time Use Research, University of Oxford, 74 Woodstock Road, Oxford OX2 6HP, UK

2 Institute of Philosophy and Sociology, Polish Academy of Sciences, Warsaw, Poland 


\section{Introduction}

Time and space were described by Kant as two organizing dimensions of human cognition, the a priori faculties of the mind that allow an individual to make sense of what he or she experiences (Kant 2003). In a broader context, these faculties not only structure individuals' perception of their lives, but also shape their everyday social reality. Temporal aspects of social life have been a popular topic in sociology, though they were addressed in a more or less direct way. In some theoretical frameworks time played an essential role as the key parameter characterizing social functioning, social change, or social organization (Sorokin and Merton 1937; Mauss 1960; Rosa 2003). In others time itself occupied the central place in the argumentation, and was the pivotal point and focus of the entire work (Zerubavel 1981; Adam 1991). Finally, for many sociologists time was neither the focus nor the fundamental aspect of their theories, and yet in mainstream sociology we still find many references to time and much emphasis on its importance (Giddens 1979, 1987; Luhmann 1982).

Sociological studies addressed also the connection between time and the key area of sociological focus-social structure. Schwartz (1974) discusses power imbalances as determinants of time organization within the social system. In particular, temporal perspectives have been theorized to reflect power structures and provide channels for social status reproduction (Adam 1991). Although the subject of intersections between time and the social structure seems to lie at the very core of sociology, there were relatively few attempts to empirically relate perspective on time to individual's social position in a wide-population study (LeShan 1952; Moore 1963). The primary objective of this paper is to fill in this gap.

Studies suggest that time perspective is socially differentiated, and that through this perspective structure may affect individual's daily choices, even with regard to such basic things as diet (Warin et al. 2015). Time orientation may bear an effect on the use of one's time and hence on individual's lifestyles. The main question is whether it is individual's time orientation, or rather their structural position that affects the actual allocation of time in daily lives. The second objective put before this paper is therefore to examine the links between time perspective and the patterns of time allocation-and to do so in relation to individual's social status. It would allow saying to what extent it is time perspective or social structure that shapes individual's patterns of time allocation, and whether time orientations may act independently of individual's social positon. The link between time perspective and time use was explored in very few studies, but they find an association between time perspective and the amount of time spend in market (Becker 1975), as well as in non-market activities (Song 2011).

The paper analyses individual's time perspective taking into account its two dimensions: future-orientation which structures one's action with regard to their anticipated long-term outcomes, and clock-time orientation as the determinant of time organization within a short term horizon of everyday activities. Future orientation in the form of deferred gratification achieved much sociological attention (Merton 1973). Clock-orientation has been researched mostly in anthropological studies (Hall 1984, 1988; Mushharbash 2007). I argue that addressing both of them together allows for a more comprehensive analysis of the links between time perspective, social structure, and daily behaviours.

The paper is structured as following: I first discuss the links between the social structure and time perspectives and outline how these might relate to individual's daily time use patterns. Next I explain the data and methodological procedures employed in the study. Results section is divided into two parts: first part shows how time perspectives relate to the three basic indicators of individual's social position: income, education, and occupational 
category. The second part of this section describes empirical links between time perspectives and actual behaviours that is between how people perceive time and how they use it. The paper concludes with a discussion of the role of time perspectives with regard to individual's life choices (behaviours) and life chances (social structure).

\section{Research Background}

Gratification deferral has been widely written about in sociology, including by such theorists as Robert Merton (1973), but most empirical data on it comes from the field of social psychology, where it is usually discussed as future-orientation. Future-orientation has been associated with a higher probability of being successful in life (Mischel et al. 1989), proactive coping with life challenges (Anagnostopoulos and Griva 2012), and lower probability of having unhealthy lifestyles or engaging in health-compromising behaviours (Rothspan and Read 1996; Keough et al. 1999; Zimbardo et al. 1997). Sociological studies show there is an association between individual social position and temporal perspective. Specifically, future-orientation has been positively associated with the level of education (Behrman and Nevzer 1997), even though educational expectations are becoming more detached for individual's social background (Goyette 2008). While future-orientation is not prevalent among people with lower social status (Warin et al. 2015; Cottle and Klineberg 1974; also in: Adams 1991), it is the attitude that might have the potential to change individual's social position. Jeremy Rifkin claims that 'those who are most present oriented are swept into the future that others have laid out for them' (Rifkin 1987, p. 166), which implies that future-oriented individuals create situations in which they might gain privilege over others. Following this reasoning one might assume that those who are present-oriented may be blamed for their limited life choices. However, social researchers have raised questions about whether it is orientation towards the future that allows an individual to obtain education, advance professionally, and gain social privileges, or rather the privileged position earlier in life that allows for being more future-oriented and waiting for greater gains. An argument presented by Hohn (1984), and echoed by Adam states that' those who hold the long-term future perspective (...) are structurally strong classes (...) [D]eferred gratification entails that one is in a position to have a trusting relationship to the future '(Adam 1991, p. 125). Future-orientation can therefore be treated either as a mechanism to achieve upward mobility or as a mechanism of reproduction of one's current privileged social position. Most likely, it is both. It is an attitude of the people who have the resources and security which permits deferring immediate rewards and waiting for the future benefits, but also of those who have enough perseverance to work for their future success despite difficulties they face at present. Needless to say, the price these two categories of people pay is very different. The reality of a labourer 'who remains linked to the life-long satisfaction of immediate needs' (Adam 1991, p. 125) might make adopting such attitude very challenging. Working for the future is a task that requires time and effort to be dedicated to it at present. Economic studies established links between future-orientation and behaviours that bring long-term benefits in terms of social position, such as education and training (Becker 1975), or health, such as exercise (Song 2011). At the same time, these research suggest higher preference for activities bringing immediate pleasure, such as watching TV, among those with higher time discount rates (Song 2011). What it implies is that individual's time perspectives might be reflected in how one uses their time on a daily basis. 
The second dimension of individual time perspective analysed in this study is clockorientation. It pertains to time organization regulated by the evenly-paced flow of time as measured by the clock, and it has frequently been used in organization studies (Das 1993). Being clock-oriented indicates a preference for rigid temporal structuring and clock-based schedules. Clock-orientation is rooted in the assumption that time constitutes a sort of a currency or a resource, which can be 'budgeted, wasted, allocated, sold or controlled' (Adam 1991, p. 104; see also: Hall 1988). It takes its beginnings in the medieval times and benedictine rule of the clock (Zerubavel 1981), and was greatly enforced in the times of industrial revolution when time was an essential element of coordination between different parts of an assembly. Time in this understanding is the sine qua non of any functionality, especially within greater and more complex systems. Terms related to capitalist economy, such as time-management, time-efficiency, waste of time or temporal opportunity costs are all embedded in the clock-dominated vision of social reality. Preference for clock-orientation might be related to individual's market activity and, specifically, time opportunity costs, which are higher for better-earning individuals (Becker 1965). Reports on the unstructured use of time characterizing the day of the unemployed (Lazarsfeld et al. 2007; Krueger and Mueller 2008) also seem to confirm the relationship between market activity and individual organization of time. Social status might therefore also be expected to be associated with the value attributed to time and the subjective need to maximize its efficiency. Furthermore, in some circles the very fact of being busy is seen as a 'badge of honour' that is an indicator of individual's professional or social success (Gershuny 2005). On the one hand, busyness might be associated with higher occupational position. On the other, having a busy schedule might increase the role of clock-orientation in daily time organization in an attempt to cope with increased temporal demands.

Research describing the benefits of future-orientation and its link to power structures have attracted much sociological attention. At the same time, due to a lack of data very little has been said about the relationship between future-orientation and how one spends time on daily basis, in particular with regard to non-market activities (Song 2011). Opposite is true for clock-orientation. It has usually been analysed with regard to daily time organization, mostly in anthropological studies, but its relationship to individual's position has not been explored. Finally, the two orientations have never been jointly analysed in a single study.

This paper models both short-horizon and long-horizon perspectives together. This is done, first of all, with an intention to see whether short-term (clock-orientation) and longterm (future-orientation) planning might work in conjunction. Both attitudes, temporal efficiency and deferring gratification, have been the temporal foundations of capitalist economy. As such they are likely to be not only positively associated with each other, but also to be positively associated with individual's social status in a market society. Modelling them together allows examining what aspects of individual's structural position either of them is associated with.

Finally, analyzing both of these attitudes with regard to individual's time allocation brings the micro-level perspective of individual's daily lives into the broader picture of structural differentiation. It unveils the more personal and, perhaps less spectacular, but no less important facets of inequality. It also allows answering an important question about the extent to which differences in individual's daily behaviours are a function of people's time orientations, representing individual's choices versus their structural position standing for life chances. 


\section{Data and Method}

Data used in this study comes from a survey funded by the National Science Center in Poland, and was collected by Ipsos Poland. Face-to-face interviews were conducted in January and February 2014. Altogether 780 individuals aged 24-60 were interviewed; seven interviews were excluded due to administrative issues which emerged during post-interviews quality checks. Respondents for the study were randomly selected using the PESEL database which is a state-administrated database that includes unique records for all people holding Polish citizenship. Sampling frame for the study was the list of all records in relevant age categories (as recorded by the PESEL numbers). In order to reflect the structure of the population in the best possible way, the sample was stratified by voivodeship, age, and gender. The sample was selected separately for men and for women, each of which was divided into 3 age strata: 24-35, 36-50, and 51-60. Proportions of these strata were calculated based on the Census data collected by the Central Statistical Office of Poland (Główny Urząd Statystyczny, GUS). Table 2 in the "Appendix" presents the GUS data on the structure of Polish population. Table 3 presents the structure of the sample for this study.

Future-orientation and clock-orientation have been well-described in earlier empirical research. Based on the analysis of existing studies on temporal orientations (Nuttin and Lens 1985; Adams and Nettle 2008; Stouthard and Peetsma 1999; Zimbardo and Boyd 1999), four indicators of future-orientation were selected for this study. A similar analysis of the studies in the field of social and cultural anthropology led to selection of four indicators of time structuring according to the clock (Hall 1984, 1990; Levine 1997). Futureorientation was measured using the following items, each of which measured the extent to which the respondent identified with the given statement on an 11-point scale: (1) I have many plans for the future; (2) I set distant objectives and work on them every day; (3) I do not give up on my objectives despite difficulties; (4) I follow my plans with persistence. Clock-orientation was measured using the following items (on an 11-point scale, same as above): (1) I am never late; (2) I plan every day in advance; (3) I always know the time; (4) I plan how much time I would spend on each activity and follow this plan. Altogether in 32 cases a respondent answered "don't know" to at least one of the indicators of either factor. In those cases general factor score could not be constructed.

Extracting the factors was done in two stages. First stage consisted of evaluation of internal consistency of the scales using Cronbach's alpha. The items that meet the 0.60 threshold were subject to further analysis. Second stage involved running exploratory factor analysis (EFA) to examine whether the items indeed could be assumed to indicate specific factors, and to what extent they loaded on the two temporal dimensions. Cronbach's alpha for indicators of future-orientation was 0.75 . In the case of clock-orientation it was lower at 0.64 , but still above the threshold. Analysis of the eigenvalues from the EFA pointed to the existence of two strong factors (see Fig. 4 in the "Appendix" for the eigenvalues of value above 1). In multivariate analyses presented further in this paper I used Bartlett scores for factors as predicted by post-estimation command (following a confirmatory factor analysis, CFA) in Stata.

First stage of analyses involved plotting a structural equation model (SEM) with a confirmatory factor analysis component. SEM was used to further validate the existence of two distinctive factors as well as to explore the relationship between the latent constructs and the indicators of individual's social status. Future-orientation and clock-orientation were theorized to constitute two distinctive aspects of individual's time perspective, and as such they 
were correlated in the model. Structural model was generated in mPlus. The path section of the model included respondent's education, occupation, and income, as well as their age and gender as independent variables. Using social status indicators separately instead of creating a combined measure allows examining the relationship between each of them and temporal perspectives. These components were shown to have independent effects on other variables (Bukodi and Goldthorpe 2013). Occupational category was recorded based on the ISCO-88 coding scheme. Due to a relatively small sample size ten single-digit ISCO groups were collapsed into the following 6 categories: (1) Managers and professionals (reference); (2) Technicians and clerks; (3) Workers in sales and services; (4) Farmers, fishermen, and forestry workers; (5) Industry workers, craftsmen, and machine operators; and (6) Individuals in low-skill simple jobs (unskilled labour force). Education was collapsed into 4 categories: (1) Gymnasium/primary school and below (reference); (2) Vocational; (3) Secondary; and (4) Tertiary. Individual income was collapsed into the categories based on its distribution in the sample: (1) bottom 20\% (reference); (2) between 20 and 50\%; (3) between 50 and 80\%; and (4) top $20 \%$ of the distribution. Gender and age were included in the model to control for basic demographic characteristics. Age was used as categorical variable with the following categories: $24-35 ; 36-50 ; 51-60$ years old. Distribution of all of these variables including the exact number of respondents in each category is given in the "Appendix" (Table 4).

Second stage of analyses involved running a set of multivariate ordinary-least square (OLS) regression models. Independent variables were: future-orientation, clock-orientation, as well as indicators of individual's social position: education, occupation, income. Gender, age, and size of place of residence were used as control variables and to represent potentially important structural conditions. Each model examined the association between these variables and how much time was allocated weekly to the following five categories of activities: (1) paid work, (2) housework, (3) use of media, (4) social life, (5) sport and physical activity, and (6) personal time, referred to in the questionnaire as 'time for myself' that is time for personal care, rest, hobbies, or other individual leisure activities. Mean and median time spent in each of these activities are given in the "Appendix" (Fig. 5).

\section{Results}

As demonstrated by descriptive statistics, levels of future-orientation were differentiated by individual's socio-economic characteristics (Fig. 1). Respondents in lowest income category, as well as those with lowest level of education or who belonged to the unskilled labour force had lowest average scores on this factor. On the other hand, managers and professionals, individuals with tertiary education or those in highest income category showed, on average, highest levels of future-orientation. Though not all differences in means were statistically significant, the differences between the highest and lowest categories were significant for all Fig. (1a-c).

Findings regarding clock-orientation were similar (Fig. 2). Individuals with lowest income or lowest educational attainment as well as those in low-skill jobs had lowest levels of clock-orientation. Also in this case differences were statistically significant between the highest and the lowest categories of each grouping variable (Fig. 2a-c).

The SEM model validated the existence of the two factors (Fig. 3). Coefficients of F1 and $\mathrm{C} 1$ (first indicators for each of the factors) were fixed to 1 . After preliminary testing F1 and F2 were assumed to have correlated errors based on the values of modification indices. Both of these variables are strongly related to future planning. After the modifications 


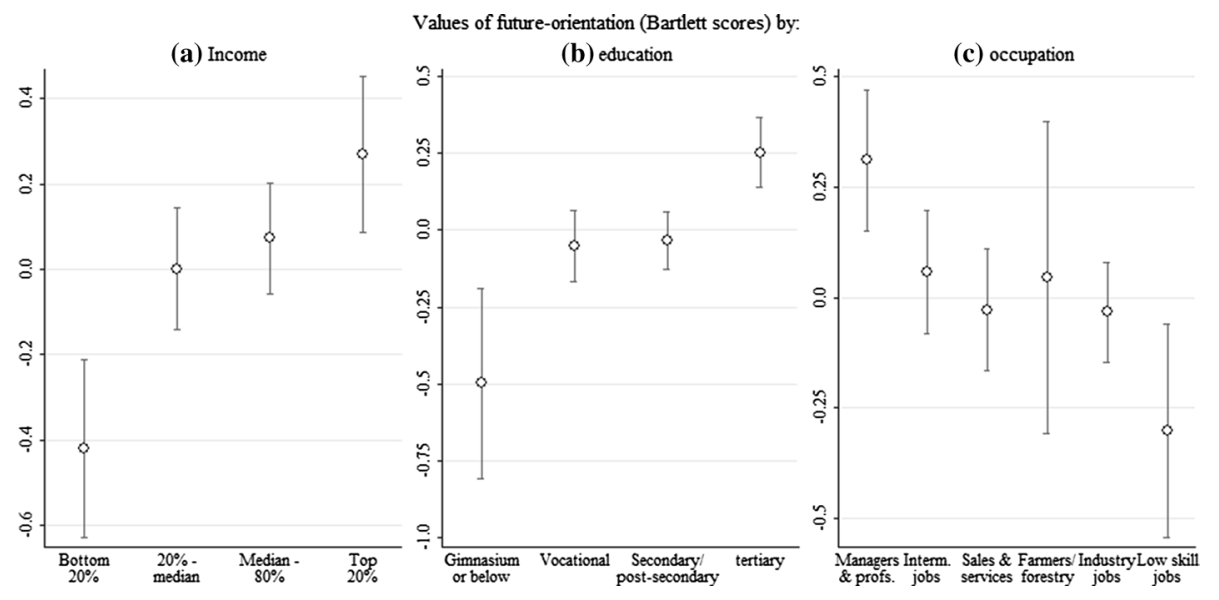

Fig. 1 Mean values of future orientation by income, education, occupation

fit statistics showed acceptable fit of the model to the data (Table 5 in the "Appendix"), and Chi square indicated a significant improvement in the model fit compared to the baseline model. The hypothesized latent variables (future orientation and clock orientation) explained a reasonable amount of the shared variance among observable variables. They were also moderately and positively correlated (Pearson's $r=0.44$ ). Positive association between the two factors held also when individual's socio-economic characteristics, such as education, occupation, and income, were controlled for. That means that even though both factors were associated with particular components of individual's social status, the link between time orientations could not be attributed to common structural characteristics alone. Long-term and short-term planning might therefore work in synchrony, perhaps even in synergy with each other, and they do so regardless of individual's structural positon.

Path section of the SEM indicated a significant association between latent constructs and selected socio-demographic variables. Education and income were both positively related to future-orientation. This is in line with earlier findings linking future-orientation with higher education (Zimbardo and Boyd 1999; Behrman and Nevzer 1997) or economic success (Bauer

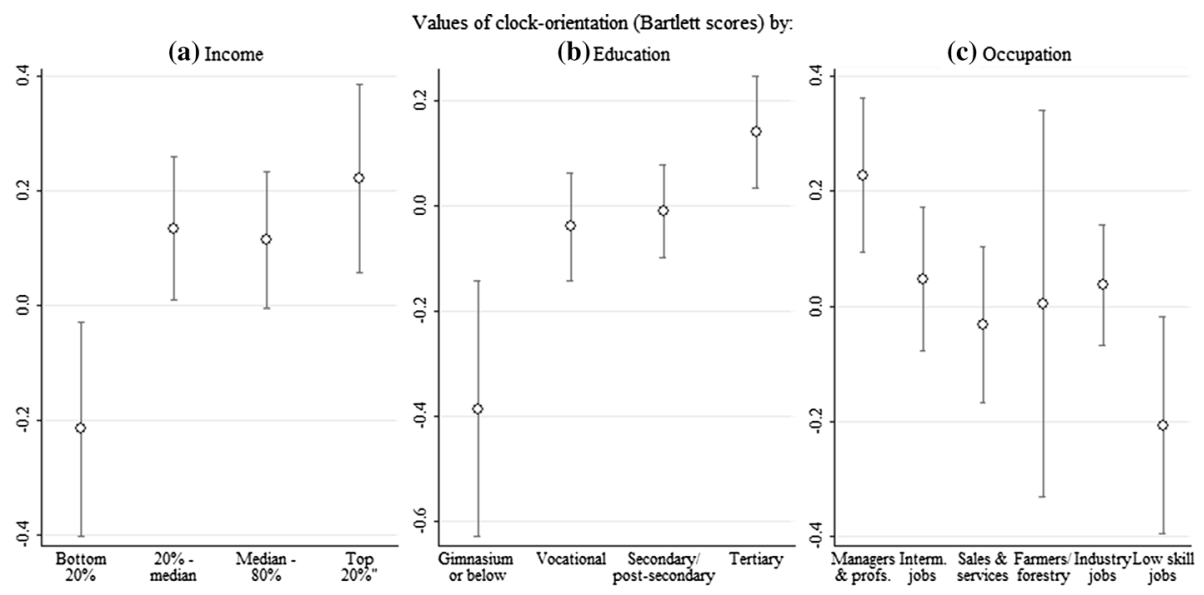

Fig. 2 Mean values of clock-orientation by income, education, occupation 


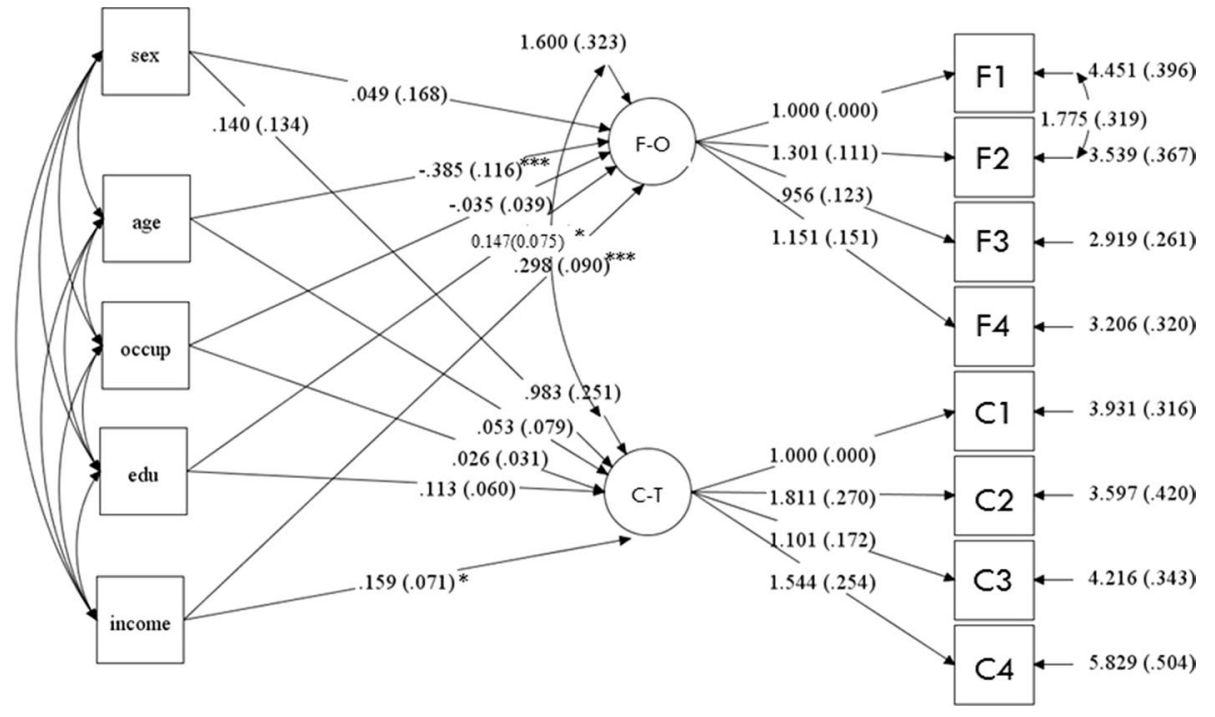

Fig. 3 Structural equation model of temporal orientations and associated socio-demographic characteristics. F-O stands for future-orientation; C-T stands for clock-time

and Chytilova 2009; Mischel et al. 1989). Occupational category, on the other hand, was not associated with future-orientation. It is, however, likely that some of occupational differentiation has been accounted for by education or income. Clock-orientation was associated with individual's income. People with higher earnings were more likely to show preference for rigid, clock-based time structuring in daily life. Importance of time control on a daily basis might be linked with higher temporal opportunity costs of those with higher income. Finally, the relationship between age and future-orientation was inverse. This is likely due to the fact that people of older age, who usually have fewer years of life ahead of them, tend to be thinking about the future less than younger people (Nurmi 1992; Lewin 1939). In case of Poland generational change might also play a role but available data did not allow determining that.

Second stage of analyses examined the link between individual's temporal perspective and time allocation. Results of multivariate regression models showed that there was a significant association between both future-orientation and clock-orientation and how people spent their time, net of their other social characteristics (Table 1). Future-orientation was positively associated with the amount of time dedicated to sport and to personal time ('time for myself'). One standard deviation increase in future-orientation was associated with $34 \mathrm{~min}$ more being dedicated to sport, and nearly $1 \mathrm{~h}(58 \mathrm{~min})$ more of personal time per week. More time spent on physical activity by future-oriented individuals might indicate willingness to invest in one's long-term health (Kahana et al. 2005). This result also supports earlier findings by Song (2011) who reported similar association using tobaccosmoking as proxy for time preference while controlling for income and education. Finally, longer duration of personal time, dedicated to relaxation, hobby or any other leisure activity, might be linked with other personality traits. Overall it is also likely to promote individual psychological wellbeing, though the topic was not explored in this study.

Clock-orientation was positively associated with the amount of time spent in paid work, and inversely associated with time spent on social life and personal time. One standard deviation increase in clock-orientation was associated with spending almost two and a half hours (147 $\mathrm{min})$ more at work on a weekly basis. It also meant cutting down on personal 


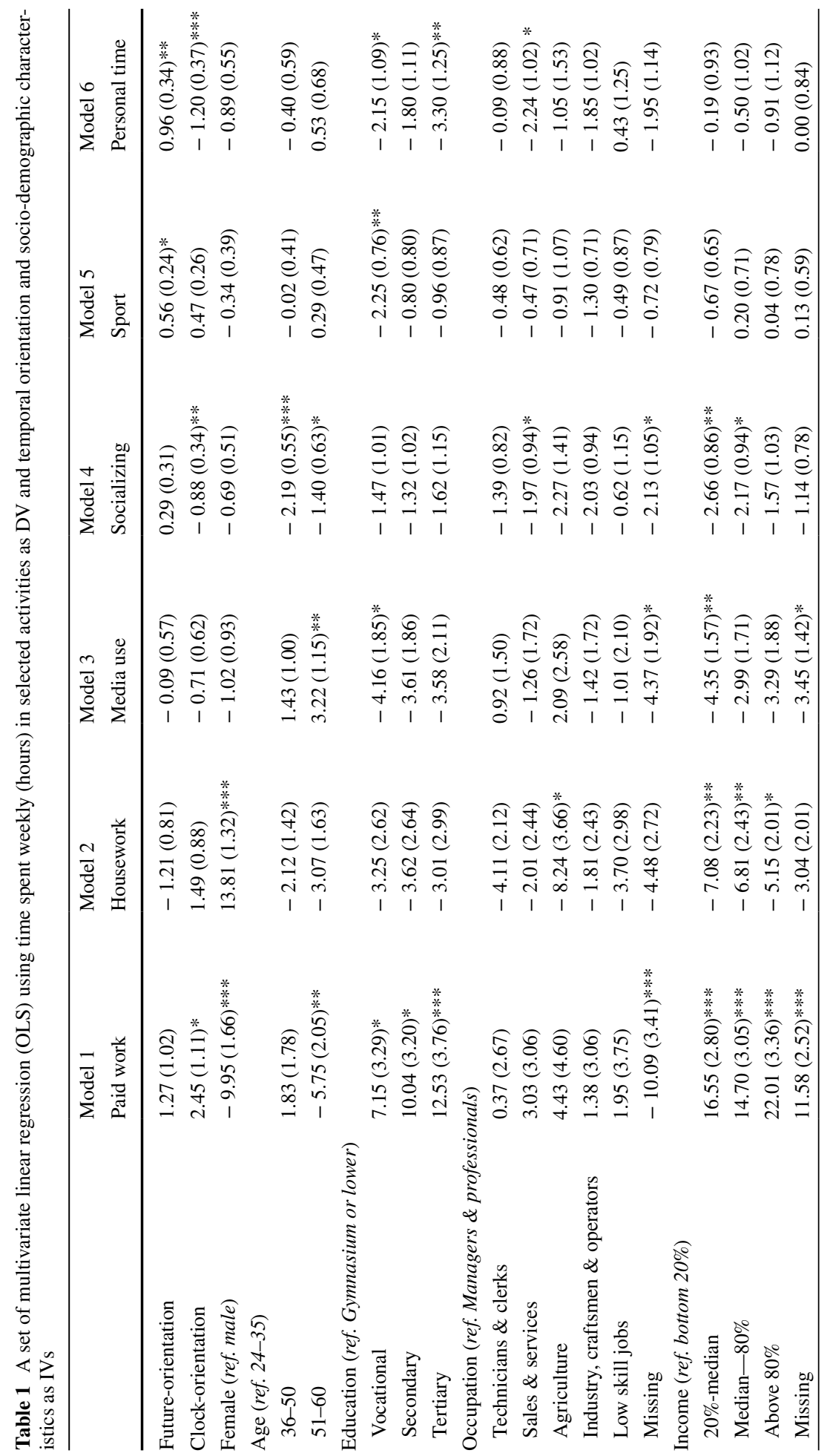




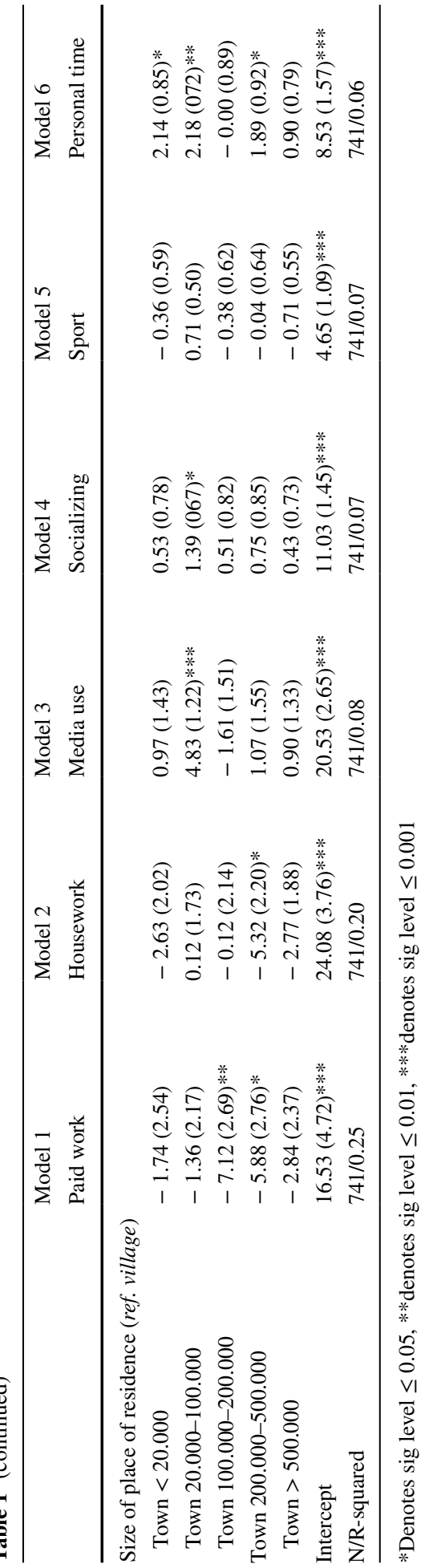


time and social life by 72 , and $53 \mathrm{~min}$, respectively. Taking into account mean duration of these activities in the sample, these differences are substantial. These findings suggest that in the case of clock-orientation time indeed might be seen as 'money' that is a resource which may be used to produce certain goods. In the case of paid work the potential payoffs are not only financial benefits but also advancements in one's career. However, time is a zero sum game and spending more time in one activity always comes at the expense of another. It seems that in the case of clock-oriented individuals, activities that are shortened are social life, and personal time. This might be associated with the preference for more structured and predictable schedules. Social and personal activities are the two examples of activities which often cannot be fitted into a pre-established schedule. Studies have shown that rigid time organization is incompatible with those areas of life, in which time efficiency is not a priority, such as, interpersonal relationships which are guided by an unstructured flow of time (Mushharbash 2007). It might be that those who are particularly attentive to an efficient use of their time and how it is structured give preference to the activities that are easier to plan and fit into their timetables.

Lastly, structural characteristics were also related to how time was spent. Individuals with higher levels of education as well as those with higher income spent more time in paid work, which is consistent with Becker's theory of time allocation (1965). Furthermore, those who earned more did less housework, which is also consistent with the same principle of spending more time on market work by better-earning individuals (Becker 1965). This result also echoes finding of earlier studies showing that less affluent people spend more time doing housework mostly due to a limited access to time-saving household appliances paired with an inability to outsource unpaid work (Hesig 2011). Lastly, as could be expected, there were significant gender differences in the amount of paid and unpaid work. The effect of size of place of residence was usually weak and not consistent.

Temporal orientations together with structural characteristics explained the greatest amount of the variance in case of paid and unpaid work, 25 and $20 \%$ respectively. Regarding individual's leisure preferences, even though temporal orientations mattered for how much time was spent in three out of four analysed leisure activities (socializing, sport, and personal time), values of R-squared were much lower. Associations between structural variables and leisure activities were few and not consistent, which suggest that personal choices, including time preferences, might play a greater role for how leisure time is spent than broader structural characteristics such as social class. However, earlier studies reported structural differentiation with regard to leisure time-use in Poland (Jarosz 2016), and lack of such association in the current study might suggest that greater level of detail is needed to explore class differences in leisure behaviours.

\section{Conclusions and Discussion}

The present study provided evidence of a link existing between individual's temporal perspectives and their social position as well as between temporal perspectives and how individuals spend their time. Specifically, it found higher average levels of future-orientation among better-educated individuals and those with higher income. The latter were also more likely to have high levels of clock-orientation. Regarding weekly time allocation, being more future-oriented was positively associated with the amount of time spent on sport and on personal activities. Clock-orientation was positively associated with the amount of time spent in paid work and inversely related to the duration of personal time and social life. The amount of time spent on media use was not related to any of the two orientations. 
Findings regarding time allocation suggest that although two temporal orientations were positively associated in the structural model, their effects on individual's time use patterns might be significant for different activities, and in some cases (personal time), they may even be opposite.

The associations between time perspectives and time-use patterns were not explained by individual's structural characteristics and they were significant for both market and non-market activities. The fact that time-use patterns were related to temporal orientations and this relationship was not explained by structural conditions suggests that individual agency, as opposed to structural conditions, might be responsible for particular lifestyle choices. One needs to remember, however, that temporal orientations are not distributed equally across the social spectrum and they are more prevalent among those in higher social positions. What it means is that they might be linked with individual's propensity for upward mobility. Time orientations were shown to be associated with individual behaviours and these, in turn, may lead to attaining higher social status. Clock-orientation was linked with spending more time in paid work; future-orientation, though not significantly associated with working time in the present study, has been shown to be linked with greater propensity for career advancements in earlier studies (Scarf 1980). Overall, the data on this topic is scarce and mostly does not allow to establish causality. More research is needed to fully explore the links between temporal perspectives, behaviours, and chances for upward mobility and, perhaps, to do so separately for different social strata. From the population health perspective, the relationship between time perspective and time spent in physical exercise is also worth more scholarly attention.

This study had several limitations. Relatively small sample size did not allow for more detailed analysis, for example with regard to the occupational categories. Furthermore, data on activities was based on respondents' declarations, not time-use diaries. Diary estimates are much more detailed and less likely to be subject to bias. Last but not least, the study did not analyse two factors that might be shadow orientations to future-orientation and clockorientation that is present-orientation and event-orientation. Both factors were operationalized in the questionnaire and examined in the initial EFA and correlation matrix analysis. However, both had low internal consistency and none of them had Eigenvalue above 1. For this reason they were not analysed further and were not discussed in this paper. Instead, it was implicitly assumed that low scores on future-orientation (in other words, lack of orientation towards the future) would in fact indicate being present-oriented. In a similar way low scores on clock-orientation would be indicative of event-orientation. The relationship between these temporal orientations might, however, be more complex and the topic merits more research attention.

Acknowledgements The author wishes to thank professor Kazimierz M. Slomczynski, Dr Alexi Gugushvili, and two anonymous reviewers for their help in development of this paper.

Funding This study was funded by the National Science Center in Poland grant number 2012/05/N/ HS6/03884, and Economic and Social Research Council grant number ES/L011662/1.

Open Access This article is distributed under the terms of the Creative Commons Attribution 4.0 International License (http://creativecommons.org/licenses/by/4.0/), which permits unrestricted use, distribution, and reproduction in any medium, provided you give appropriate credit to the original author(s) and the source, provide a link to the Creative Commons license, and indicate if changes were made.

\section{Appendix}

See Tables 2, 3, 4 and 5 and Figs. 4 and 5 


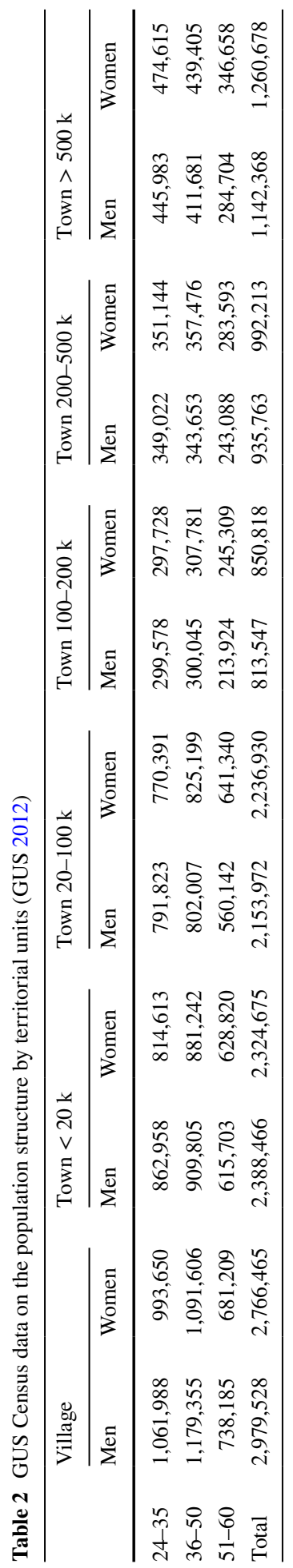




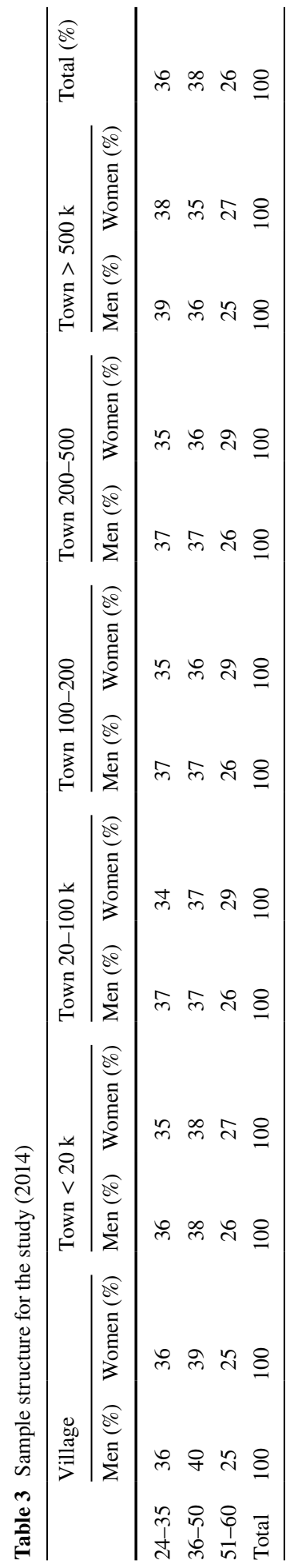


Table 4 Distribution and number of respondents in selected sociodemographic variables

Table 5 Fit indices of the SE model

\begin{tabular}{|c|c|c|}
\hline & Frequency & Valid in \% \\
\hline \multicolumn{3}{|l|}{ Sex } \\
\hline Male & 378 & 49 \\
\hline Female & 395 & 51 \\
\hline \multicolumn{3}{|l|}{ Age brackets } \\
\hline $24-35$ & 279 & 36 \\
\hline $36-50$ & 290 & 38 \\
\hline $51-60$ & 204 & 26 \\
\hline \multicolumn{3}{|l|}{ Education } \\
\hline Gymnasium or lower & 51 & 7 \\
\hline Vocational & 228 & 30 \\
\hline Secondary & 296 & 38 \\
\hline Tertiary & 198 & 26 \\
\hline \multicolumn{3}{|l|}{ Income } \\
\hline Bottom 20\% & 93 & 12 \\
\hline $20 \%$-median & 146 & 19 \\
\hline Median-80\% & 107 & 14 \\
\hline Top $20 \%$ & 79 & 10 \\
\hline Missing & 348 & 45 \\
\hline \multicolumn{3}{|l|}{ Occupation } \\
\hline Managers \& professionals & 100 & 13 \\
\hline Technicians \& clerks & 146 & 19 \\
\hline Sales \& service jobs & 141 & 18 \\
\hline Farmers, forestry, fishermen & 32 & 4 \\
\hline Industry, craftsmen \& operators & 209 & 27 \\
\hline Low skill jobs & 60 & 8 \\
\hline Missing & 85 & 11 \\
\hline
\end{tabular}

\begin{tabular}{ll}
\hline Number of free parameters & 36 \\
Akaike (AIC) & $14,198.666$ \\
Bayesian (BIC) & $14,342.628$ \\
Sample-size adjusted BIC & $14,228.396$ \\
Chi Square test of model fit & 147.657 \\
Degrees of freedom & 48 \\
$P$ value & 0.0000 \\
RMSEA & \\
Estimate & 0.072 \\
$90 \%$ C.I. & 0.059 \\
& 0.085 \\
Probability RMSEA $\leq .05$ & 0.004 \\
CFI & 0.886 \\
TLI & 0.839 \\
Chi square for the baseline M. & 942.460 \\
Degrees of freedom & 68 \\
$P$ value & 0.0000 \\
SRMR & 0.046 \\
\hline
\end{tabular}




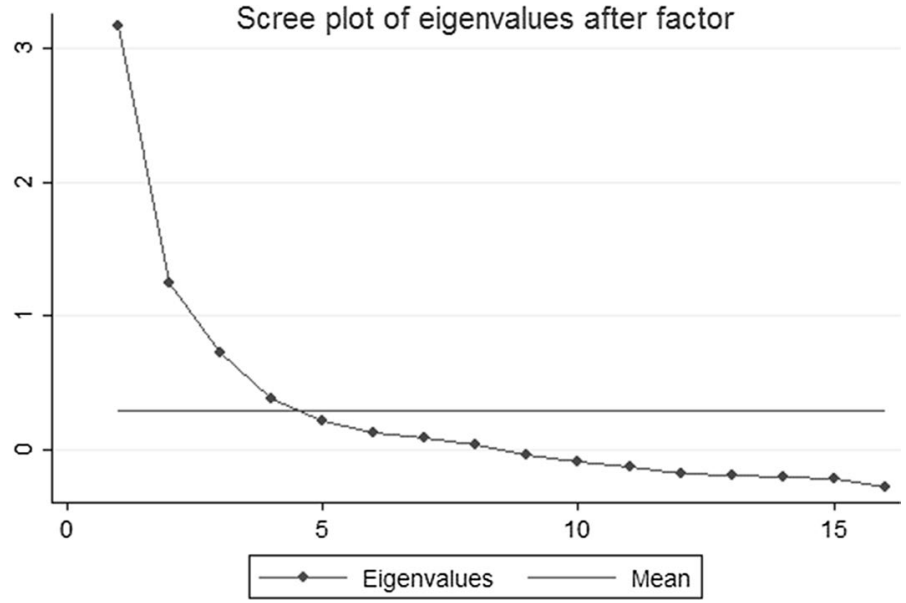

Fig. 4 Eigenvalue plot for Exploratory Factor Analysis (EFA)

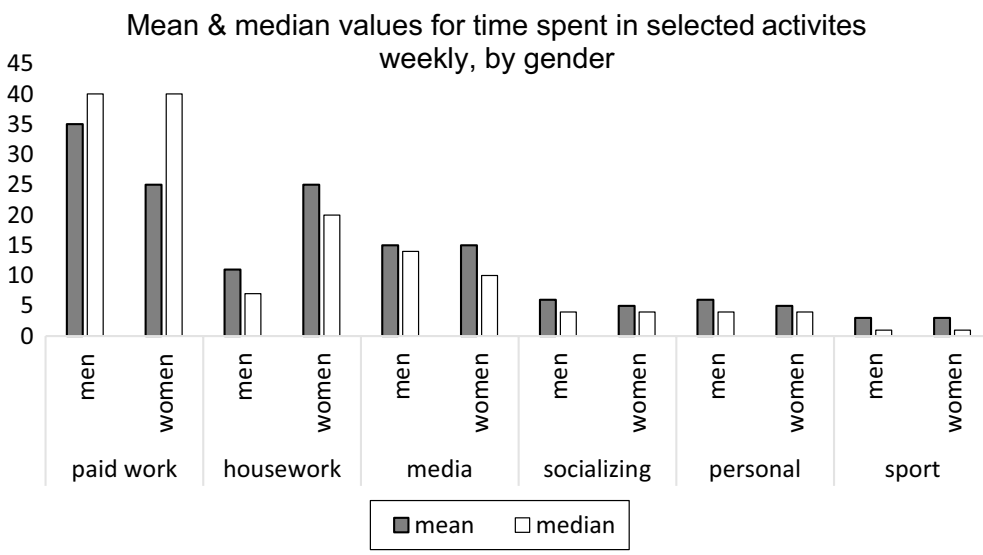

Fig. 5 Mean and median time in hours in selected activities, weekly, by gender

\section{References}

Adam, B. (1991). Time and social theory. Cambridge: Polity Press.

Adams, J., \& Nettle, D. (2008). Time perspective, personality and smoking, body mass, and physical activity: An empirical study. British Journal of Health Psychology, 14, 83-105.

Anagnostopoulos, F., \& Griva, F. (2012). Exploring time perspective in greek young adults: Validation of the Zimbardo time perspective inventory and relationships with mental health indicators. Social Indicators Research, 106(1), 41-59.

Bauer, M. \& Chytilova, J. (2009). The impact of Education on the Subjective Discount Rate in Ugandan Villages, IZA Discussion Papers, 4057.

Becker, G. (1965). A theory of allocation of time. Economic Journal, 75, 493-517.

Becker, G. (1975). Human capital. Chicago: University of Chicago Press.

Behrman, J., \& Nevzer, S. (1997). The social benefits of education. Ann Arbor: University of Michigan Press. 
Bukodi, E., \& Goldthorpe, J. (2013). Decomposing 'social origins': The effects of parents' class, status, and education on the educational attainment of their children. European Sociological Review, 29(5), 1024-1039.

Cottle, T., \& Klineberg, S. (1974). The present of things future: Explorations of time in human experience. New York: Free Press.

Das, T. (1993). Time in management and organizational studies. Time \& Society, 2(2), 267-274.

Gershuny, J. (2005). Busyness as the badge of honor for the new superordinate working class. Social Research: An International Quarterly, 72(2), 287-314.

Giddens, A. (1979). Central problems in social theory. Action, structure and contradiction in social analysis. London: Macmillan.

Giddens, A. (1987). Time and social organization. In A. Giddens (Ed.), Social theory and modern sociology (pp. 140-165). Cambridge: Polity Press.

Główny Urząd Statystyczny [GUS] (2012). Census data for Poland.

Goyette, K. (2008). College for some to college for all: Social background, occupational expectations, and educational expectations over time. Social Science Research, 37(2), 461-484.

Hall, E. (1984). La danse de la vie-Temps culturel, temps vécu. Paris: Seuil.

Hall, E. (1988). The hidden dimension. New York: Bantam Doubleday Dell Publishing.

Hall, E. (1990). Understanding cultural differences. Minneapolis: Consortium.

Hessig, J.-P. (2011). Who does more housework: Rich or poor? American Sociological Review, 76(1), 74-99.

Hohn, H. (1984). Die Zerstörung der Zeit: Wie aus einem göttlichen Gut eine Handelsware wurde. Frankfurt am Main: Fischer Alternativ.

Jarosz, E. (2016). The duration and dynamics of leisure among the working population in Poland. A timeuse approach. World Leisure Journal, 58, 44-59.

Kahana, E., Kahana, B., \& Zhang, (2005). Motivational antecedents of preventive proactivity in late life: Linking future orientation and exercise. Motivation and Emotions, 29(4), 443-464.

Kant, I. (2003). Critique of pure reason. Mineola: Dover Publications.

Keough, K., Zimbardo, P., \& Boyd, J. (1999). Who's smoking, Drinking and using drugs? Time Perspective as a Predictor of Substance Use, Basic and Applied Psychology, 21(2), 149-164.

Krueger, A. \& Mueller, A. (2008). The lot of the unemployed: A time use perspective, IZA Working Paper No. 3490.

Lazarsfeld, P., Jahoda, M., \& Zeisel, H. (2007). Bezrobotni Marienthalu. Warszawa: Oficyna Naukowa.

LeShan, L. (1952). Time orientation and social class. The Journal of Abnormal and Social Psychology, 47(3), 589-592.

Levine, R. (1997). A geography of time. London: Oneworld Publications.

Lewin, K. (1939). Field theory and experiment in social psychology: Concepts and methods. The American Journal of Sociology, 44, 868-897.

Luhmann, N. (1982). The future cannot begin. Temporal structures in modern society. In N. Luhmann (Ed.), The differentiation of society. New York: Columbia University Press.

Mauss, M. (1960). Sociologie et anthropologie. Paris: Les Presses Universitaires de France.

Merton, R. (1973). The sociology of science: Theoretical and Empirical investigations. Chicago: The University of Chicago Press.

Mischel, W., Shoda, Y., \& Rodriguez, M. (1989). Delay of gratification in children'. Science, 244, 933-938.

Moore, W. (1963). Man, time, and society. New York: Wiley.

Mushharbash, Y. (2007). Boredom, time, and modernity: An example from aboriginal Australia. American Anthropologist, 109(2), 307-317.

Nurmi, J. (1992). Age differences in adult life goals, concerns, and their temporal extension: A life course approach to future-oriented motivation. International Journal of Behavioral Development, 15, 487-508.

Nuttin, J., \& Lens, W. (1985). Future time perspective and motivation: Theory and research method. Leuven: Leuven University Press.

Rifkin, J. (1987). Time Wars. New York: Henry Holt.

Rosa, H. (2003). Social acceleration: Ethical and political consequences of a desynchronized high-speed society. Constellations, 10(1), 3-33.

Rothspan, S., \& Read, S. (1996). Present versus future time perspective and HIV risk among heterosexual college students. Health Psychology, 15, 131-134.

Scarf, M. (1980). Unfinished business: Pressure points in the lives of women. New York: Doubleday Books.

Schwartz, B. (1974). Waiting, exchange, and power: The distribution of time in social systems. American Journal of Sociology, 79(4), 841-870.

Song, Y. (2011). Time preference and time use: Do smokers exercise less? Labour, 25(3), 350-369. 
Sorokin, P., \& Merton, R. (1937). Social time: A methodological and functional analysis. American Journal of Sociology, 42(5), 615-629.

Stouthard, M., \& Peetsma, T. (1999). Future-time perspective: Analysis of a facet-designed questionnaire. European Journal of Psychological Assessment, 15, 99-105.

Warin, M., Zivkovic, T., Moore, V., Ward, P., \& Jones, M. (2015). Short horizons and obesity futures: Disjuncture between public health interventions and everyday temporalities. Social Science and Medicine, 128, 309-315.

Zerubavel, E. (1981). Hidden rhythms: Schedules and calendars in social life. Chicago: University of Chicago Press.

Zimbardo, P., \& Boyd, J. (1999). Putting time in perspective: A valid, reliable individual-differences metric. Journal of Personality and Social Psychology, 77, 1271-1288.

Zimbardo, P., Keough, K., \& Boyd, J. (1997). Present time perspective as a predictor of risky driving. Personality and Individual Differences, 23, 1007-1023. 